\title{
PENERAPAN COGNITIVE BEHAVIORAL ART THERAPY (CBAT) UNTUK MENURUNKAN AGRESIVITAS PADA REMAJA LPKA X
}

\author{
Reza Fahlevi ${ }^{1}$, Debora Basaria ${ }^{2}$ dan Santy Yanuar Pranawati ${ }^{3}$ \\ ${ }^{1}$ Fakultas Psikologi, Universitas Tarumanagara, Jakarta \\ Email: reifahlevipsy@gmail.com \\ ${ }^{2}$ Fakultas Psikologi, Universitas Tarumanagara, Jakarta \\ Email: deborab@fpsi.untar.ac.id \\ ${ }^{3}$ Fakultas Psikologi, Universitas Tarumanagara, Jakarta \\ Email: pranawatisanty@gmail.com
}

\begin{abstract}
ABSTRAK
Remaja merupakan periode transisi antara masa anak-anak dan masa dewasa yang melibatkan perubahanperubahan pada aspek biologis, kognitif maupun psikososial. Remaja yang tidak dapat mengelola emosinya secara efektif dapat menyebabkan perasaan tertekan, kemarahan, kurang mampu meregulasi emosi yang selanjutnya menimbulkan berbagai masalah dalam akademik, kenakalan remaja seperti tawuran dan penyalahgunaan obat. Cognitive Behavioral Art Therapy (CBAT) adalah bentuk terapi di mana partisipan terlibat dalam cara berpikir tentang masalah mereka. Partisipan dapat mempersepsikan masalah mereka dari perspektif baru melalui gambar dan sadar terhadap perasaan dan pikirannya. CBAT biasa digunakan dalam praktik untuk memberikan penanganan pada kasus untuk mengatasi masalah emosi dan perasaan seperti marah, cemas, pasca trauma, dan berbagai kelompok depresi dan penyakit kronis. Untuk saat ini, CBAT belum banyak diterapkan dalam penanganan kasus klinis terutama di Indonesia pada kasus agresi pada remaja. Tujuan dari penelitian ini adalah partisipan dapat mengendalikan rasa marah sehingga dapat menurunkan perilaku agresi yang seringkali ditampilkan dalam bentuk perilaku negatif seperti marah, kasar, mengejek, atau memukul. Desain dalam penelitian ini adalah kuasieksperimen. CBAT dilakukan sebanyak 10 sesi untuk menurunkan agresivitas. Terdapat 6 partisipan dalam penelitian yang merupakan hasil screening awal dengan menggunakan alat ukur agresivitas buss dan perry, skala moral Kohlberg, Edward Personal Personality Scale (EPPS), serta tes draw a person yang menunjukkan adanya karakteristik agresi yang tinggi pada partisipan. Evaluasi dilakukan dengan mengukur kembali tingkat agresivitas dengan alat ukur agresivitas buss dan perry, dan tes draw a person. Hasil intervensi menunjukkan adanya penurunan pada skala agresivitas keenam partisipan setelah diberikan intervensi CBAT.
\end{abstract}

Kata kunci: cognitive behavioral art therapy, agresivitas, dan remaja LPKA

\begin{abstract}
Adolescence is a transition period between childhood and adulthood which involves changes in biological, cognitive and psychosocial aspects. Adolescents who cannot manage their emotions effectively can cause feelings of depression, anger, lack of ability to regulate emotions which in turn causes various problems in academics and juvenile delinquency such as brawl and drug abuse. Cognitive Behavioral Art Therapy (CBAT) is a form of therapy in which participants engage in ways of thinking about their problems. Participants can perceive their problems from a new perspective through pictures and be aware of their feelings and thoughts. CBAT is commonly used in cases to overcome emotional and feelings problems such as anger, anxiety, post-trauma, and various groups of depression and chronic illness. At present, CBAT has not been widely applied in the handling of clinical cases, especially in Indonesia in cases of aggression in adolescents. The purpose of this study is to help participants control their anger to reduce aggressive behavior that is often displayed in the form of negative behavior such as anger, abusive, bullying, or hitting. The design of this study is quasi-experimental. CBAT was carried out over as many as 10 sessions to reduce aggression. There were 6 participants in the study which were the results of initial screening using measuring tools of buss and perry aggression, Kohlberg's moral scale, Edward Personal Personality Scale (EPPS), and draw a person test that showed high aggression characteristics in the participants. Evaluation is done by measuring the level of aggression using the buss and perry aggression questionnaire, and draw a person test. The results of the intervention showed a decrease in the scale of the aggression of the six participants after being given the CBAT intervention.
\end{abstract}

Kata kunci: cognitive behavioral art therapy, aggression, and LPKA adolescents 


\section{PENDAHULUAN}

\section{Latar Belakang}

Remaja merupakan periode transisi antara masa anak-anak dan masa dewasa yang melibatkan perubahan-perubahan biologis, kognitif, dan psikososial. Perubahan biologis, kognitif, dan psikososial yang dialami remaja dapat berkisar mulai dari perkembangan fungsi seksual hingga proses berpikir abstrak hingga kemandirian. Remaja dibagi menjadi dua, yakni remaja awal dan remaja akhir. Remaja awal berkisar seputar sekolah menengah pertama dan meliputi perubahan ke masa-masa pubertas, sementara remaja akhir mengacu pada masa dekade kehidupan kedua, seperti minat terhadap karir, kencan, dan eksplorasi identitas (Santrock, 2010). Papalia, Feldman, dan Olds (2009) mengatakan bahwa remaja adalah suatu periode yang berada di antara masa kanak-kanak dan masa dewasa ketika individual dihadapkan dengan serangkaian hambatan dan tantangan masa perkembangan. Masa remaja ini biasanya dimulai pada usia 12 atau 13 tahun dan umumnya berakhir pada akhir belasan atau awal dua puluhan. Meskipun pada remaja terjadi peningkatan pada kemampuan kognitif dan kesadaran, namun banyak juga remaja yang tidak dapat mengelola emosinya secara lebih efektif, sebagai akibatnya remaja rentan untuk mengalami depresi, kemarahan, kurang mampu meregulasi emosi yang selanjutnya dapat memicu munculnya berbagai masalah seperti kesulitan akademis, penyalahgunaan narkoba, dan kenakalan remaja seperti tawuran, berkelahi dan penyalahgunaan obat (Santrock, 2010).

Pada umumnya, anak yang memasuki masa remaja berada pada fase pencarian identitas diri (Santrock, 2010). Dalam tahap perkembangan tersebut, tak jarang remaja mengalami hambatan atau bahkan melakukan perilaku yang keliru yang dapat merugikan mereka, baik untuk dirinya sendiri maupun orang lain. Perilaku yang dicerminkan dapat berupa perilaku yang positif dan perilaku yang negatif, salah satunya yaitu berupa perilaku kenakalan. Kenakalan pada anak dimaknai sebagai suatu bentuk perilaku yang tidak sesuai dengan norma-norma yang hidup di tengah masyarakat. Pada umumnya, kenakalan merupakan produk konstitusi defektif dari mental dan emosi, yaitu mental dan emosi anak yang belum matang (labil) dan rusak (defektif) sebagai akibat proses pengkondisian oleh lingkungan yang buruk (Kartono, 2008).

Perilaku yang sering terjadi pada anak adalah perilaku agresi. Perilaku agresi secara psikologis cenderung menyerang sesuatu yang dipandang sebagai hal yang mengecewakan, menghalangi atau menghambat. Perilaku ini terjadi pada masa perkembangan, karena pada masa inilah seorang anak sudah mulai merasa ingin mengetahui dan ingin melakukan sesuatu yang dia inginkan walaupun tanpa dia sadari sesuatu yang dia lakukan itu dapat berdampak negatif pada dirinya sendiri ataupun pada orang lain (Santrock, 2010). Pengertian tentang agresi dikemukakan oleh Berkowitz (Armstrong, 2005) agresi merupakan segala bentuk perilaku yang dimaksudkan untuk menyakiti seseorang baik secara fisik maupun mental, atau mencelakakan individu lain yang tingkah lakunya tidak diinginkan.

Perilaku agresi pada remaja muncul ketika remaja merasa adanya ancaman, marah, gusar, atau frustrasi (Hurlock, 2004). Perilaku agresi merupakan reaksi normal pada anak-anak atau remaja ketika mereka merasa tidak nyaman, ketika mereka ingin melindungi diri mereka, atau ketika mereka ingin mencapai suatu tujuan tertentu namun tidak mengetahui bagaimana cara yang lebih baik untuk meraihnya. Selain itu, perilaku agresi juga merupakan cara khas anak kecil untuk menunjukkan kepada orang lain bahwa mereka tidak suka pada apa yang dilakukan orang lain terhadap mereka. Akan tetapi, seiring dengan bertambahnya usia mereka, khusunya ketika berkembang menjadi remaja seharusnya menjadi semakin mampu menggunakan cara-cara yang lebih tepat untuk meraih tujuannya, sehingga tidak perlu bertindak dengan cara yang agresi (Hatta, 2016). Perilaku agresi menjadi bagian dari tahapan perkembangan mereka dan sering kali 
menimbulkan masalah, baik itu di rumah, sekolah ataupun dalam suatu kelembagaan yang mana disuatu tempat tersebut dia dapat berinteraksi terutama dengan orang lain. Diharapkan setelah melewati usia 11 tahun, anak sudah lebih dapat mengendalikan dirinya untuk tidak menyelesaikan masalah dengan perilaku agresi (Santrock, 2010).

Berkowitz (Nisbett, 2017) menjelaskan bahwa perilaku agresi merupakan tindakan non verbal ataupun verbal yang memiliki tujuan menyakiti orang lain. Perilaku agresi secara fisik (nonverbal) antara lain memukul, menggigit, mencubit, menendang, menginjak, melempari orang dengan benda, dan sebagainya. Sedangkan secara psikis (verbal), diantaranya mengucapkan kata-kata hinaan atau mengejek, memaki dengan kata-kata kotor, melecehkan, mengancam, membentak orang yang lebih tua, atau bahkan memerintah orang lain seenaknya. Dengan adanya perubahan baik dari sisi seksual, psikologis maupun sosial membuat masa remaja yang memiliki emosi yang tidak stabil seringkali menjadi masa-masa rawan terjadinya perilaku agresi yang diakibatkan kurangnya bimbingan orang tua, kurangnya perhatian guru, pengaruh lingkungan, pergaulan yang tidak baik atau kurangnya perhatian dari orang tua karena adanya pola asuh yang dapat mempengaruhi semua ini (Pohan, 1986). Oleh sebab itu pada remaja perlu memahami strategi dalam penyelesaian masalah dan penanganan emosional untuk dapat secara adaptif mengatasi emosi-emosi negatif dengan cara menghindari situasi negatif yang membuat marah dan terlibat dalam aktivitas yang dapat mengalihkan perhatiannya seperti dengan menggunakan intervensi cognitive behavioral art therapy (CBAT). Perilaku agresi salah satunya dapat diintervensi dengan cognitive behavioral art therapy (CBAT). CBAT merupakan kombinasi dari dua terapi, yaitu cognitive behavioral therapy dan art therapy. CBAT merupakan salah satu bentuk terapi yang menggunakan gambar sebagai media dan cognitive behavioral therapy sebagai pendekatannya. Secara konseptual, menggambar adalah serangkaian kegiatan yang dilakukan menggunakan media gambar, dimana klien dapat menyampaikan keadaan pikiran dan perasaannya secara bebas tanpa adanya rasa cemas dan tidak nyaman akibat dari pengaruh lingkungan (Morris, 2014; Oster \& Crone, 2004; Rubin, 2001). CBAT adalah bentuk terapi di mana klien terlibat dalam cara berpikir tentang masalah mereka. Klien dapat mempersepsikan masalah mereka dari perspektif baru melalui gambar dan sadar terhadap perasaan dan pikirannya (Alavinezhad, Mousavi, \& Sohrabi, 2014).

Dalam hal ini, CBAT biasa digunakan dalam praktik untuk memberikan penanganan pada kasus untuk mengatasi masalah emosi dan perasaan seperti marah, cemas, pasca trauma, dan berbagai kelompok depresi dan penyakit kronis. CBAT secara umum memiliki beberapa fungsi mendasar antara lain: (a) Membantu dalam membangun konsep sehat dan strategi penyesuaian diri untuk meningkatkan harapan hidup dan meningkatkan kehidupan, (b) memahami cara berpikir, seperti berbicara intrapersonal pada diri (inner speech) dan gambaran mental sebagai penyebab munculnya suatu perilaku, dan (c) memberikan rekomendasi atau solusi pada generasi berikutnya untuk membantu individu yang lain dalam mengatasi tekanan (stress) atau meningkatkan strategi (copying). CBAT memiliki fungsi dalam hal ini untuk menyediakan beberapa macam keterampilan (skills) untuk melibatkan kemampuan dalam fungsi kognitif dan meningkatkan pola pikir dan cara penyelesaian masalah dengan menggunakan media seni (art) (Rosal, 2018).

Mekanisme penggunaan CBAT dengan menggunakan seni memberikan kebebasan kepada individu untuk membuat beberapa gambar (image) dan kemudian dijembatani untuk menemukan solusi dari masalah yang dialami oleh individu (Rosal, 2018). CBAT juga memiliki dampak yang positif dengan penggunaan art therapy di sekolah, terutama pada anak-anak yang memiliki gangguan dalam perilaku seperti conduct dan melanggar aturan (Rozum, 2001). CBAT juga 
diketahui memiliki dampak positif pada penghuni lapas (Breiner, Gussak, Aufderheide, Bouyea, \& Tuomisto, 2011). Kedua penelitian menunjukkan adanya peningkatkan positif pada aspek perilaku seperti perilaku prososial. Pada Penelitian (Breiner et al., 2011) penggunaan CBAT untuk manajeman marah pada tahanan di US menggunakan metode CBT dengan menambahkan art therapy untuk mempermudah klien mengekspresikan pikiran dan perasaannya. Penelitian art therapy diintegrasikan dengan CBT pun dilakukan dalam penelitian (alavinezhad et al., 2014) dalam penanganan emosi marah dan harga diri pada anak dengan agresi menunjukkan bahwa art therapy dan CBT efektif dapat menurunkan kemarahan dan meningkatkan harga diri pada anak yang memiliki perilaku agresi. Menurut Liebmann (2008) dengan menggunakan art therapy dapat mengarahkan kemarahan ke dalam bentuk gambar (image) dan juga individu dapat mengekspresikan perasaannya dengan cara tidak melakukan kekerasan (non violent) dengan cara dialihkan melalui bentuk atau simbol dan juga melalui proses berpikir agar individu dapat menyalurkan ide dan solusi.

Intervensi kelompok dengan pendekatan CBAT dilakukan agar partisipan dapat mengendalikan rasa marah (anger management) sehingga dapat menurunkan kecenderungan perilaku agresi remaja yang seringkali menampilkan perilaku negatif seperti marah, kasar, mengejek, atau memukul. Dengan metode terapi cognitive behavioral art therapy (CBAT) diharapkan partisipan dapat belajar mengekspresikan perasaan dengan bentuk gambar dengan cara partisipan memahami bagaimana perasaan marah dan agresi dapat mempengaruhi tindakan. Diharapkan dengan intervensi kelompok ini partisipan dapat mendapatkan kesadaran (insight) terhadap perilaku agresi dan melepaskan perasaan dan emosi negatif yang berdampak terhadap lingkungan dengan cara dan strategi yang lebih baik seperti mengeskspresikan perasaan dengan cara yang positif, meningkatkan kemampuan untuk menyelesaikan masalah dan mempelajari cara melakukan relaksasi.

\section{Rumusan Masalah}

Rumusan masalah dalam penelitian ini adalah, "Apakah penerapan cognitive behavioral art therapy (CBAT) efektif dalam menurunkan agresi remaja LPKA X?"

\section{METODE PENELITIAN}

\section{Partisipan}

Partisipan dalam penelitian ini berjumlah 6 orang (M, AM, W, RA, AK, dan MF) yang merupakan rujukan dari petugas LPKA $X$ dikarenakan keenam partisipan seringkali menampilkan perilaku negatif, seperti melakukan perilaku agresi secara verbal maupun fisik kepada teman-temannya. Sebelum pemeriksaan, partisipan diminta untuk mengisi lembar biodata dan inform consent kesediaan mengikuti penelitian.

\section{Prosedur Penelitian}

Sebelum melakukan penelitian, penulis melakukan observasi dan wawancara terhadap keenam partisipan untuk melihat gambaran kepribadian dan perilaku agresif yang ditampilkan oleh para partisipan. Selain melalui observasi dan wawancara, partisipan diminta untuk mengisi alat ukur agresivitas Buss dan Pery (Garofalo, 2018). Partisipan juga diminta untuk mengisi tes Edward Personal Personality Scale (EPPS) untuk melihat kebutuhan dan dinamika kepribadian partisipan. Selain itu, partisipan diminta untuk mengisi kuesioner skala moral Kohlberg yang telah diadaptasi oleh Budiningsih (2001). Keenam partisipan juga diminta untuk menggambar orang (draw a person) untuk melihat gambaran kepribadian partisipan. 


\section{Desain Penelitian}

Penelitian ini dilakukan dengan desain kuasi-eksperimen. Dengan demikian, pengalaman pengalaman spesifik tiap partisipan dapat dieksplorasi terkait kejadian atau situasi yang membuat partisipan menjadi frustasi dan marah. Kemudian intervensi cognitive behavioral art therapy (CBAT) dilakukan untuk mengurangi perasaan marah dan pikiran agresif para partisipan ketika merasa frustasi dan marah. Pengukuran tingkat agresivitas dilakukan di sesi awal (pretest) dan sesi akhir (post-test). Pre-test diberikan pada awal peneliti melakukan pengambilan data awal, untuk melihat tingkatan agresivitas partisipan sebelum diberikan intervensi, kemudian setelah peneliti memberikan intervensi CBAT, di akhir sesi terminasi dilakukan pengukuran post-test untuk melihat penurunan agresivitas partisipan setelah diberikan intervensi CBAT.

\section{HASIL DAN PEMBAHASAN}

\section{Gambaran partisipan}

Secara umum, keenam partisipan menunjukkan adanya tingkat agresivitas tinggi berdasarkan pengukuran skala agresivitas buss dan perry (Garofalo, 2018), tes inventori EPPS, dan tes gambar orang (DAP).

Tabel 1.

Gambaran Agresivitas Partisipan

\begin{tabular}{|c|c|c|c|c|}
\hline \multirow[t]{2}{*}{ No } & \multirow[t]{2}{*}{ Partisipan } & \multicolumn{3}{|c|}{ Gambaran partisipan melalui pengukuran } \\
\hline & & Agresivitas & EPPS & DAP \\
\hline 1 & $\mathrm{M}$ & $\begin{array}{c}104 \\
\text { (Tinggi) }\end{array}$ & $\begin{array}{c}\text { Agg } \\
++\end{array}$ & $\begin{array}{l}\text { Kesulitan dalam mengendalikan diri, } \\
\text { kecenderungan agresi, ingin menjadi dominan. }\end{array}$ \\
\hline 2 & AM & $\begin{array}{c}102 \\
\text { (Tinggi) }\end{array}$ & $\begin{array}{l}\text { Agg } \\
+\end{array}$ & $\begin{array}{l}\text { Kecenderungan agresi, kesulitan menyesuaikan } \\
\text { diri, sensitive terhadap lingkungan, dan } \\
\text { berorientasi pada diri sendiri }\end{array}$ \\
\hline 3 & $\mathrm{~W}$ & $\begin{array}{c}91 \\
\text { (Sedang) }\end{array}$ & $\begin{array}{l}\text { Agg } \\
+\end{array}$ & $\begin{array}{l}\text { Kecenderungan agresi, kesulitan dalam } \\
\text { mengendalikan diri, peka terhadap kritikan, dan } \\
\text { berorientasi pada diri sendiri }\end{array}$ \\
\hline 4 & RA & $\begin{array}{c}92 \\
\text { (Sedang) }\end{array}$ & $\begin{array}{l}\text { Agg } \\
++\end{array}$ & $\begin{array}{l}\text { Kecenderungan agresi, impuls yang lemah dan } \\
\text { tidak terarah, hipersensitif terhadap pendapat } \\
\text { orang lain, kesulitan dalam mengendalikan diri }\end{array}$ \\
\hline 5 & AK & $\begin{array}{c}103 \\
\text { (Tinggi) }\end{array}$ & $\begin{array}{l}\text { Agg } \\
++\end{array}$ & $\begin{array}{l}\text { Ingin menjadi pusat perhatian, kecenderungan } \\
\text { berperilaku agresi, kesulitan mengendalikan } \\
\text { diri, adanya tendensi didalam diri }\end{array}$ \\
\hline 6 & MF & $\begin{array}{c}89 \\
\text { (Sedang) }\end{array}$ & $\begin{array}{l}\text { Agg } \\
+\end{array}$ & $\begin{array}{l}\text { Impuls dan dorongan yang kuat didalam diri, } \\
\text { kecenderungan berperilaku agresi, kesulitan } \\
\text { dalam mengendalikan diri, hipersensitif } \\
\text { terhadap pendapat orang lain. }\end{array}$ \\
\hline
\end{tabular}

\section{Pelaksanaan intervensi}

Dalam intervensi cognitive behavioral art therapy (CBAT), kegiatan cognitive behavioral art therapy di desain untuk mengajarkan partisipan $\mathrm{M}, \mathrm{AM}, \mathrm{W}, \mathrm{RA}, \mathrm{AK}$, dan MF menyadari dan memahami pikiran perasaan yang dirasakannya, serta menentukan kejadian atau peristiwa yang menjadi penyebab keenam partisipan menjadi frutasi dan marah. Selain itu juga, keenam partisipan diajarkan melakukan reduksi ketegangan (relaksasi) dengan cara kegiatan breathing exercise atau mindfulness agar para partisipan dapat melepas ketegangan dan pemikiran negatif. Intervensi yang digunakan dalam kelompok ini menggunakan pendekatan group therapy. Sesi ini dilakukan sebanyak 10 sesi yang dilakukan sebanyak dua kali dalam satu minggu. Menurut Tyndall-lind, Landreth, \& Giordano (2001) pada umumnya teknik terapi berlangsung antara 5-21 sesi, namun untuk sesi singkat biasanya dapat menggunakan 6-12 sesi. Menurut durasi yang 
efektif untuk melakukan terapi kelompok dengan pendekatan art therapy adalah satu jam sampai dengan satu setengah jam.

Desain intervensi cognitive behavioral art therapy (CBAT), diadaptasi dari tahapan (Namdari, 2012; Bulchalter 2009), terapi menggambar tersebut dimodifikasi dari berbagai pendekatan yang didalamnya terdapat tiga tahapan, yaitu tahap warm up, mindfulness/relaxation, drawing. CBAT dalam penelitian ini dilakukan secara berkelompok dengan pertimbangan agar partisipan merasa nyaman karena mengalami permasalahan yang sama dengan partisipan lain. Kegiatan terapi dalam kelompok juga diharapkan memberi efek positif karena terdapat proses saling menguatkan dan menerima informasi baru yang positif dari setiap partisipan yang ada di dalam kelompok.

\section{Hasil Intervensi}

Tabel 2.

\section{Gambaran Hasil Intervensi}

\begin{tabular}{|c|c|c|}
\hline Sesi & Tahapan & Hasil Intervensi \\
\hline $\begin{array}{l}\text { Psikoedukasi } \\
\text { "Emosi } \\
\text { marah } \\
\text { berdampak } \\
\text { pada perilaku }\end{array}$ & $\begin{array}{l}\text { Reduksi } \\
\text { Ketegangan } \\
\text { "Draw a comic } \\
\text { style figure" }\end{array}$ & $\begin{array}{l}\text { Partisipan diminta untuk menggambarkan tokoh atau karakter komik yang } \\
\text { menggambarkan perasaan dan perilaku partisipan ketika sedang marah. } \\
\text { - } \quad \text { Dari keenam partisipan yang membuat tokoh atau karakter, semua gambar } \\
\text { partisipan menunjukkan karakter dengan kesan yang menyeramkan dan } \\
\text { semua partisipan menampilkan karakter dengan sifat yang menunjukkan } \\
\text { perilaku agresif seperti mata yang seram, goresan yang tajam, gigi runcing } \\
\text { maupun kuku yang tajam. } \\
\text { Dari keenam gambar, partisipan yang terlihat mengekspresikan gambarnya } \\
\text { tanpa kendali adalah partisipan AM, AK, RA, dan MF. }\end{array}$ \\
\hline agresi & $\begin{array}{l}\text { Rekonstruksi } \\
\text { Kognitif }\end{array}$ & $\begin{array}{l}\text { Partisipan diminta untuk saling mendiskusikan mengenai definisi marah } \\
\text { - Semua partisipan dapat mendefinisikan definisi marah sesuai dengan } \\
\text { pemikiran mereka. Namun demikian diantara keenam partisipan yang paling } \\
\text { baik memberikan jawaban adalah RA dan MF. Sedangkan jawaban yang } \\
\text { paling sederhana adalah M dan AM. }\end{array}$ \\
\hline \multirow{3}{*}{$\begin{array}{l}\text { Sesi } 2 \\
\text { (Explore } \\
\text { anger } \\
\text { triggers and } \\
\text { describe how } \\
\text { they respond } \\
\text { to conflict) }\end{array}$} & $\begin{array}{l}\text { Reduksi } \\
\text { ketegangan } \\
\text { "draw a } \\
\text { cartoon like } \\
\text { their character } \\
\text { \& muscle } \\
\text { relaxation" }\end{array}$ & $\begin{array}{l}\text { Partisipan diminta untuk menggambar karakter yang menggambarkan diri mereka. } \\
\text { - Dari keenam partisipan yang menunjukkan perubahan gambar kearah positif } \\
\text { dari sesi } 1 \text { adalah M, dan RA. Sedangkan keempat partisipan lainnya, masih } \\
\text { menunjukkan gambaran karakter yang memiliki kesan agresi, yaitu AM, W, } \\
\text { AK, dan MF. Gambar masih menunjukkan goresan agresi dan kontrol } \\
\text { terhadap ekspresi warna yang berlawanan (konflik). } \\
\text { Pada penerapan muscle relaxation, partisipan yang cepat dalam melepas } \\
\text { ketegangan adalah M, W, dan RA. Sedangkan partisipan yang sulit dalam } \\
\text { melepas ketegangan adalah AK, dan AM. Dari tahapan muscle relaxation } \\
\text { partisipan merasakan perubahan didalam dirinya menjadi lebih tenang dan } \\
\text { positif. }\end{array}$ \\
\hline & & $\begin{array}{l}\text { Partisipan diminta mendiskusikan apa yang ia rasakan ketika ia dapat membuang } \\
\text { emosi negatif. } \\
\text { - Partisipan M menyatakan "ia lebih tenang dan menyadari perilakunya yang } \\
\text { salah selama ini". Sama halnya "AM dan AK juga mengatakan hal yang sama } \\
\text { dirasakan oleh M bahwa AM dan AK merasa tenang dan lebih legah". }\end{array}$ \\
\hline & $\begin{array}{l}\text { Rekonstruksi } \\
\text { Kognitif }\end{array}$ & $\begin{array}{l}\text { - W mendapat pemikiran baru bahwa ketika marah tidak harus selalu } \\
\text { melakukan perlawanan ataupun mengikuti emosinya. } \\
\text { RA menyadari bahwa menyimpan dendam, pengalaman buruk merupakan hal } \\
\text { yang negatif dan tidak ada gunanya. Sama halnya MF juga menyadari bahwa } \\
\text { rasa sedih, kecewa dan marah merupakan hal yang negatif dan merusak } \\
\text { pikiran dan perasaannya. } \\
\text { Kesimpulan keenam partisipan merasakan manfaat positif dari melepaskan emosi } \\
\text { negatif melalui gambar ataupun melalui muscle relaxation pada sesi-2. }\end{array}$ \\
\hline $\begin{array}{l}\text { Sesi } 3 \\
\text { (Thought }\end{array}$ & $\begin{array}{l}\text { Reduksi } \\
\text { Ketegangan }\end{array}$ & $\begin{array}{l}\text { Partisipan diminta untuk menggambar hal yang membuat partisipan merasa kesal } \\
\text { dan marah. }\end{array}$ \\
\hline & "draw emotion & - $\quad \mathrm{M}$ dan AM menggambar orang yang memasukkan (mencobloskan) M ke \\
\hline
\end{tabular}




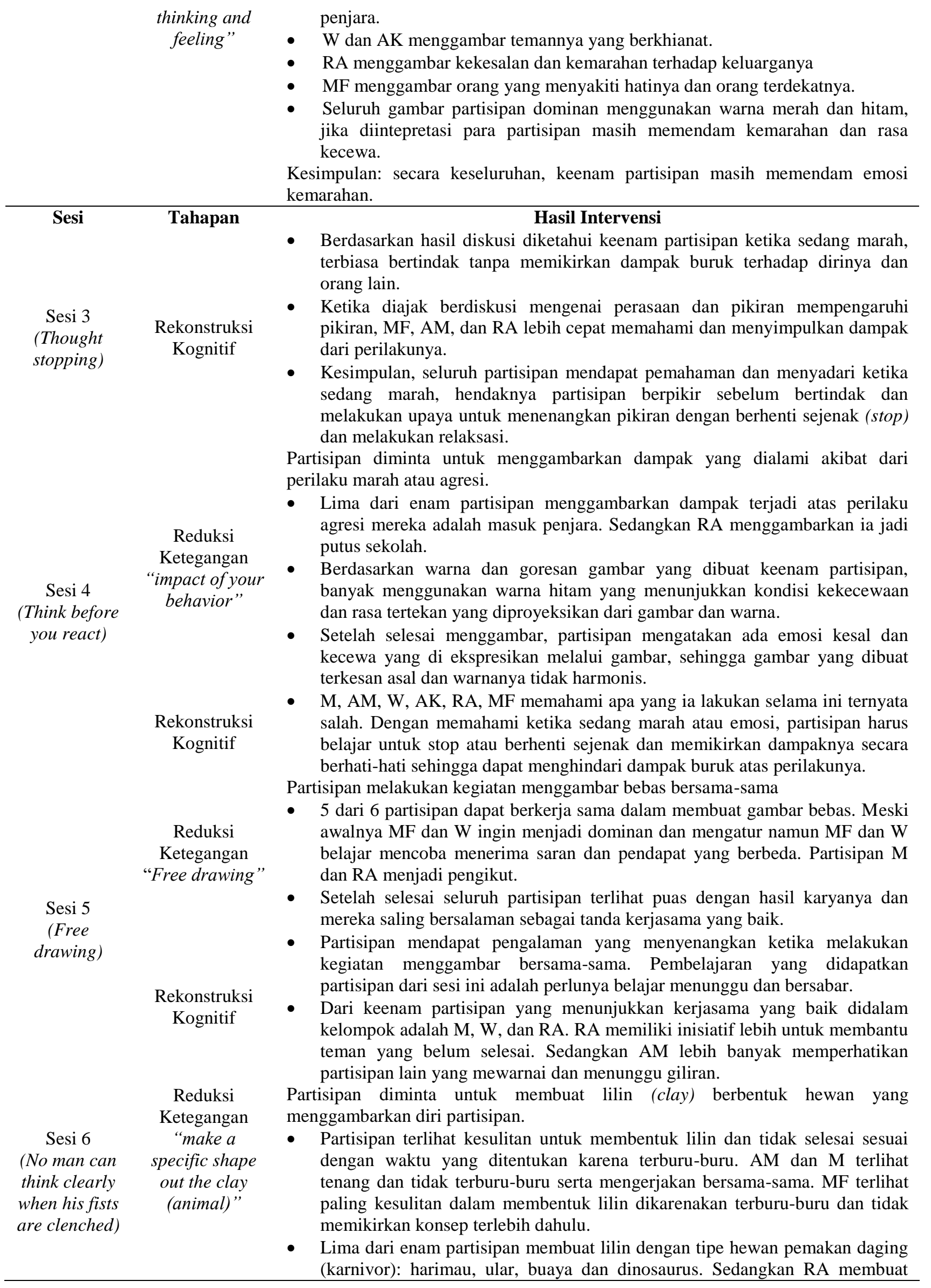


kura-kura yang merupakan hewan herbivora.

- Partisipan terlihat dapat sabar menanti dan berbagi clay.

Kesimpulan : Partisipan sudah mulai berkerjasama dan saling berbagi setelah sesi 5 dilakukan. Partisipan terlihat semakin akrab dan saling membantu.

\begin{tabular}{c}
\hline Sesi \\
Sesi 6 \\
(No man can \\
think clearly \\
when his fists \\
are clenched)
\end{tabular}

\section{Tahapan}

Mandala

\section{Sesi 7}

(Mask making)

Sesi 8

(Treat others only in ways that you are willing to be treated in the same exact situation)
Reduksi Ketegangan

Rekonstruksi Kognitif

Reduksi

Ketegangan "Role Play"

Rekonstruksi Kognitif

\section{Hasil Intervensi}

- Empat dari enam partisipan menggambar mandala dengan content (isi) yang sama. Mengesankan gambar yang estetik.

- AK mengekspresikan mandalanya dengan warna yang bercampur (blends), dan terlihat abstrak. AK mengatakan bahwa pikirannya saat itu sedang kalut. Setelah membuat mandala, AK menjadi lebih tenang.

- $\quad$ RA membuat mandala yang mengesankan keseimbangan.

Kesimpulan : pada sesi mandala, partisipan sudah mampu fokus dan mengenali emosinya. Hanya saja AK perlu diberikan penyaluran emosi yang lebih besar untuk mengekspresikan emosinya.

Partisipan diberikan topeng putih, dan kemudian partisipan diminta untuk mewarnai topeng tersebut sesuai keinginan mereka.

- Semua partisipan terlihat antusias dan semangat ketika memukai sesi mewarnai topeng. M dan RA yang paling bersemangat diantara lain.

- Partisipan dapat berbagi dan menunggu giliran penggunaan cat. Partisipan semakin menyadari perlunya berkerja sama didalam suatu kelompok.

- Keseluruhan partispan dapat mengeskpresikan emosi dan warna favoritnya kedalam goresan di topeng sebagai media katarsis.

- Semua partisipan memahami pentingnya untuk merenung dan menginstropeksi diri untuk melihat kekurangan dan kelebihan.

Kesimpulan: Melalui topeng, partisipan jadi lebih memahami proyeksi dirinya.

Partisipan diminta memilih tema dan melakukan role play.

- M memilih tema orang yang melakukan bullying.

- $\mathrm{AM}$ dan RA memilih tema kekerasan. Ketika diminta untuk memainkan peran, AM menolak. AM mengatakan malu dan hanya mau menceritakan saja tindakan yang dilakukan oleh karakter itachi.

- W, AK dan MF memilih tema begal.

- Kelima partisipan dapat melakukan peran sesuai tema yang dipilih dengan baik. Meski AM menolak untuk ikutan melakukan role play.

- Keenam partisipan terlihat senang dengan kegiatan hari ini. M menyampaikan bahwa "ketegangan hari ini menjadi hilang karena mereka bisa tertawa". Kemudian AK menambahkan melalui role play jadi bisa lebih paham karakter orang.

Kesimpulan : Keenam partisipan dapat melepas ketegangan dan emosinya melalui bermain peran. Meski AM menolak mengikuti role play, namun AM dapat menceritakan dampak negatif atas tema kekerasan, dan menyampaikan perasaan dan pikiran ketika ia menjadi korban.

- M mengatakan bahwa "karakter keras seperti madon hendaknya dijauhi, biarin dia sendirian tidak punya teman". Kemudian ia mendapat pelajaran mengenai perlunya untuk memikirkan orang lain sebelum bertindak, memikirkan bagaimana kalo saya diposisi orang lain

- AM memberikan pesan untuk tidak menyakiti hati orang lain, kita harus menyadari jika hendak diperlakukan baik oleh orang lain maka kita harus memperlakukan orang lain juga dengan baik.

- W menyampaikan bahwa pada sesi ini ia mendapatkan pembelajaran mengenai ketika marah "ia seharusnya tidak melampiaskan ke orang lain. Hendaknya memikirkan perasaan dan pikiran orang lain ketika bertindak".

- AK mengatakan "sama seperti W "ketika marah jangan mengambil keputusan terburu-buru, tapi mencoba diselesaikan dengan cara yang baik, jika tidak bisa AK akan mencoba untuk menenangkan diri”.

- $\quad$ RA menyadari bahwa apa yang ia lakukan selama ini merupakan hal yang keliru, ia ketika marah dan kesal tidak seharusnya melampiaskan ke orang lain. 
- MF mengatakan bahwa ia dapat menyadari perlunya untuk memikirkan kondisi orang lain dari sudut pandang MF.

Kesimpulan: keenam partisipan mulai memahami dirinya dan berusaha untuk melihat sudut pandang orang lain.

\begin{tabular}{|c|c|c|}
\hline Sesi & Tahapan & Hasil Intervensi \\
\hline $\begin{array}{c}\text { Sesi } 9 \\
\text { (Conquering } \\
\text { others take } \\
\text { force, } \\
\text { conquering } \\
\text { yourself is }\end{array}$ & $\begin{array}{l}\text { Reduksi } \\
\text { ketegangan } \\
\text { "draw my } \\
\text { journey" }\end{array}$ & $\begin{array}{l}\text { Dari keenam partisipan yang sudah sesuai membuat pemetaan dalam konsep } \\
\text { sungai kehidupan adalah AK, AM, RA, dan MF. } \\
\text { Dari pemilihan dan ekspresi warna yang digunakan keempat partisipan } \\
\text { terlihat lebih harmonis, dan adanya pengendalian diri. } \\
\text { Kesimpulan: Keenam partisipan sudah mampu merefleksi kenangan dan } \\
\text { pengalaman positif yang dialami dari kecil hingga sekarang dan keenam partisipan } \\
\text { mampu menentukan goal kedepannya. } \\
\text { - Melalui pemahaman mengenai psikoedukasi narkoba, keenam partisipan lebih } \\
\text { menyadari bahaya dan dampaknya, sehingga diharapkan dapat membantu } \\
\text { dalam mejauhkan partisipan dari konsumsi narkoba kedepannya. }\end{array}$ \\
\hline true strength) & $\begin{array}{c}\text { Rekonstruksi } \\
\text { Kognitif }\end{array}$ & $\begin{array}{l}\text { - Melalui mengenang hal positif dan menentukan goal hidup, keenam partisipan } \\
\text { menunjukkan pemikiran yang lebih positif dan optimis di waktu yang akan } \\
\text { datang }\end{array}$ \\
\hline & & $\begin{array}{l}\text { Kesimpulan : Partisipan sudah mampu memahami kondisi dirinya dan menilai hal } \\
\text { positif yang dimilikinya serta mampu menentukan goal kedepannya setelah dari } \\
\text { LPKA. }\end{array}$ \\
\hline \multirow[t]{2}{*}{$\begin{array}{l}\text { Sesi } 10 \\
\text { (Evaluation } \\
\text { Termination) }\end{array}$} & Evaluasi & $\begin{array}{l}\text { - Dari keenam partisipan menunjukkan adanya perubahan dalam skala } \\
\text { agresifitas. } \\
\text { Keenam partisipan juga terlihat perubahan pada emosi menjadi lebih positif } \\
\text { yang dapat dinilai dalam dari tahapan reduksi ketegangan emosi melalui } \\
\text { gambar. }\end{array}$ \\
\hline & & $\begin{array}{l}\text { Kesimpulan: CBAT mampu diterapkan untuk kasus kelompok dalam penanganan } \\
\text { kasus agresi pada remaja. }\end{array}$ \\
\hline
\end{tabular}

\section{Diskusi}

Penurunan agresivitas pada skala agresivitas Buss dan Perry (Garofalo, 2018) terjadi pada semua partisipan. Penurunan tingkat agresivitas paling banyak terjadi pada AM dan RA dari skor awal tinggi menjadi kategori sedang. Sedangkan partisipan lain mengalami penurunan pada skor poin. Perubahan dalam tes grafis yang terjadi dapat dilihat dari perubahan gambar orang (DAP) yang dibuat oleh para peserta berdasarkan ukuran, letak, bentuk, arah, dan coretan garis yang dilakukan oleh para peserta. Hal-hal yang berubah pada gambar yang dibuat oleh peserta termasuk ukuran gambar orang secara keseluruhan yang menjadi lebih besar dan proporsional, letaknya lebih ke arah tengah kertas, hilangnya bentuk bagian tubuh yang tajam, serta hilangnya garis yang bergerigi dan shading. Hal tersebut mengidikasikan adanya penurunan dalam perilaku agresif dan menunjukkan bahwa para peserta lebih mampu untuk mengendalikan dirinya. Proses menggambar memunculkan emosi tertentu pada partisipan. Gambar dapat digunakan sebagai media ekspresi. Proses tersebut dianggap sebagai cara untuk berkomunikasi yang menekankan pada gambar dan memfasilitasi proses berpikir untuk mengeksplorasi perasaan, mendamaikan konflik emosional, lebih membuat seseorang aware terhadap dirinya, mengelola perilaku, mengembangkan keterampilan sosial, meningkatkan orientasi realitas, mengurangi kecemasan, serta meningkatkan harga diri (Burt, 2012; Farokhi, 2011; O’lenic \& Arman, 2005; Ul-Hasanah, Borualogo, \& Wahyudi, 2018).

Pada partisipan mengalami perubahan pada bagian mulut (verbal). Perilaku agresi salah satu perilakunya adalah lekas marah (Hamilton, 2011). Dengan perubahan pada gambar pada area mulut menjadi indikator perubahan perilaku agresi. Selain tingkat agresifitas terdapat beberapa aspek yang meningkat selama proses terapi, seperti kepercayaan diri dan sosialisasi yang ditunjukkan pada partisipan. Hal ini ditunjukkan dengan semakin besarnya gambar dan kesan yang tidak menyeramkan pada DAP post-test setelah selesai intervensi. Selain itu, juga terdapat 
perubahan yang positif pada relasi antar keenam partisipan. Para partisipan juga menjadi lebih kooperatif dan lebih toleran terhadap satu sama lain. Para partisipan mampu berdiskusi dan bekerja sama, serta membuat suatu keputusan bersama tanpa menunjukkan perilaku agresif.

Penelitian ini menyatakan bahwa penerapan CBATdapat menurunkan agresi pada remaja di LPKA X Jakarta. Akan tetapi terdapat beberapa kekurangan dalam penelitian ini, salah satunya adalah jumlah partisipan hanya enam, sehingga belum dapat menyimpulkan dan belum mampu di generalisasi. Sesi yang diberikan juga tidak banyak dan hanya sepuluh sesi, sehingga hanya dapat melihat dampak dalam jangka waktu pendek secara umum saja. Kedua, desain penelitian ini tidak memiliki variabel kontrol dan kriteria inklusif mengenai tinggi atau rendahnya skor agresi. Dengan tidak adanya grup pembanding antara partisipan yang diberikan terapi dan partisipan terkontrol atau memiliki skor kualitas hidup yang tinggi dengan yang rendah, sulit untuk menerima konklusi bahwa CBAT merupakan variabel yang berperan dalam menurunkan agresi secara kausal. CBAT dapat digunakan sebagai terapi untuk menurunkan agresi pada remaja, khususnya di LPKA. Faktor yang mendukung penurunan agresi adalah dengan mengubah pemikiran dan pandangan partisipan terhadap dirinya menjadi lebih positif serta pemahaman mengenai coping strategy terhadap masalah emosi yang dialami, selain itu sikap kooperatif dan saling mendukung dari sesama remaja menjadi pendukung dalam efektifitas terapi CBAT secara bekelompok.

\section{KESIMPULAN DAN SARAN}

Intervensi cognitive behavioral art therapy (CBAT) dapat dilakukan secara intervensi kelompok. Dari keenam partisipan dengan menggunakan pendekatan cognitive behavioral art therapy terbukti dapat mengurangi agresifitas pada keenam partisipan, yaitu, M, AM, W, AK, RAF, dan MFH. Penurunan tingkat agresifitas tersebut dapat dilihat dengan menggunakan alat ukur skala agresivitas Buss dan Perry (Garofalo, 2018) serta Draw a Person (DAP). Hal ini juga dilengkapi dengan wawancara dengan keenam partisipan dan menggunakan rancangan observasi individu yang mempelihatkan penurunan perilaku agresif.

\section{Saran kepada peneliti selanjutnya}

Apabila penelitian serupa akan dilakukan, disarankan peneliti menambah sesi aktivitas dalam kelompok sehingga partisipan lebih belajar menghargai dan menerima perbedaan. Hasil penelitian akan lebih efektif jika dilakukan kegiatan rileksasi pada setiap sesinya, sehingga para partisipan dapat lebih fokus untuk mengikuti kegiatan cognitive behavioral art therapy agar hasilnya mampu lebih signifikan. Hal lain yang mampu disarankan adalah dengan menambah jumlah partisipan. Hal ini dapat dilakukan agar memudahkan peneliti dalam mengeneralisasikan kesimpulan dari penelitian.

\section{Ucapan Terima Kasih (Acknowledgement)}

Penulis berterima kasih kepada partisipan yang terlibat dalam penelitian ini. Penulis juga mengucapkan terima kasih kepada Kepala LPKA X berserta petugas LPKA yang memberikan izin dan kesempatan melakukan penelitian.

\section{REFERENSI}

Alavinezhad, R., Mousavi, M., \& Sohrabi, N. (2014). Effects of Art Therapy on Anger and Selfesteem in Aggressive Children. Procedia-Social and Behavioral Sciences, 113, 111-117. https://doi.org/10.1016/j.sbspro.2014.01.016

Armstrong, T. (2005). Evaluating the competing assumptions of Gottfredson and Hirschi's (1990) A General Theory of Crime and psychological explanations of aggression. Western Criminology Review, 6(1), 12-21. Retrieved from http://wcr.sonoma.edu/v6n1/manuscripts/armstrong.pdf

Breiner, M. J., Gussak, D. E., Aufderheide, D., Bouyea, E., \& Tuomisto, L. (2011). Creating an 
Art Therapy Anger Management Protocol for Male Inmates Through a Collaborative Relationship. International Journal of Offender Therapy and Comparative Criminology, 56(7), 1124-1143. https://doi.org/10.1177/0306624x11417362

Buchalter, Susan. (2009). Art Therapy Techniques and Applications. London: Jessica Kingsley Publishers.

Budiningsih, A. (2001). Penalaran moral remaja dan beberapa faktor budaya yang berhubungan dengannya: analisis karakteristik siswa SLTP dan SMU di Yogyakarta. Disertasi. PPSUniversitas Negeri Malang.

Burt, I. (2012). An Innovative Approach to Working With Angry Adolescents Using Therapeutic Principles and Martial Arts. Ideas and Research You Can Use: Vistas, 55(1), 1-10.

Farokhi, M. (2011). Art therapy in humanistic psychiatry. Procedia-Social and Behavioral Sciences, 30, 2088-2092. https://doi.org/10.1016/j.sbspro.2011.10.406

Garofalo, C. (2018). Aggression Questionnaire. Encyclopedia of Personality and Individual Differences, 63(3), 1-3. https://doi.org/10.1007/978-3-319-28099-8_809-1

Hamilton, M. A. (2011). Verbal agression: understanding the psychological antecendents and social consequense. Journal of Language and Social Social Consequences, 31,1-8. https://doi.org/10.1177/0261927X11425032.

Hatta, K. (2016). Trauma dan pemulihannya. Banda Aceh: Dakwah Ar-raniry Press.

Hurlock, E.B. (2004). Psikolologi perkembangan suatu pendekatan sepanjang rentang kehidupan. Jakarta: Penerbit Erlangga.

Namdari, R. (2012). The Comic Face of Anger: Art Therapy and Cognitive-Behavioral Therapy in an Anger Treatment Program. Thesis. Concordia University.

Nisbeet, R.E. (2017). Though and feeling: cognitive alteration of feeling states. United Kingdom: Routledge.

O'lenic, C., \& Arman, J. (2005). Anger management for adolescents: A creative group counseling approach. VISTAS: Compelling Perspectives on Counseling, 2005 (Article 10), 55-58. Retrieved from https://www.counseling.org/Resources/Library/Selected Topics/Bullying/Vistas05.art10.pdf.

Pohan, M.I. (1986). Masalah anak dan anak bermasalah. Jakarta: Intermedia.

Tyndall-lind, A., Landreth, G. L., \& Giordano, M. A. (2001). Intensive group play therapy with child witnesses of domestic violence. International Journal of Play Therapy, 10(1), 5383. https://psycnet.apa.org/doi/10.1037/h0089443

Ul-Hasanah, F. N., Borualogo, I. S., \& Wahyudi, H. (2018). Efektivitas Cognitive Behavior Art Therapy Untuk Meningkatkan Self-Esteem Remaja Obesitas Yang Menjadi Korban Bullying. Journal of Psychological Science and Profession, 1(3), 9-20. https://doi.org/10.24198/jpsp.v1i3.14969 